\title{
Electromagnetic pollution maps as a resource for assessing the risk of emissions from mobile communications antennas
}

\author{
Vladimir Henao Céspedes ${ }^{1}$, Luis Fernando Díaz Cadavid², Yeison Alberto Garcés Gómez ${ }^{3}$ \\ ${ }^{1,3}$ Unidad de Formación en Ciencias Naturales y Matemáticas, Universidad Católica de Manizales, Colombia \\ ${ }^{2}$ Department of Electrical and Electronics Engineering and Computer Sciences, \\ Universidad Nacional de Colombia-Sede Manizales, Colombia
}

\begin{tabular}{l} 
Article Info \\
\hline Article history: \\
Received Aug 22, 2019 \\
Revised Feb 7, 2020 \\
Accepted Mar 8, 2020 \\
\hline Keywords: \\
Electromagnetic pollution \\
Non-ionizing radiation \\
Pollution map \\
Environment \\
Health
\end{tabular}

Health

\begin{abstract}
Electromagnetic pollution has taken on importance in recent decades, as interest is growing in knowing how the proliferation of mobile communication devices can affect the environment and generate health problems in the population. In this document, a systematic review of the methodologies for measuring electromagnetic radiation is carried out with a view to generating pollution profiles. It also develops a novel methodology for measuring electromagnetic pollution (EMP) in urban areas, and is validated with a case study using a map of EMP in the city of Manizales (Colombia), determining the spatial distribution of radiation levels. In order to generate the map, EMP measurements were carried out in the bands of local mobile telephone operators, in addition to the LPWAN (low power wide area network) LoRaWAN and Sigfox networks, Wi-Fi, and those related to IoT technologies.
\end{abstract}

Copyright $@ 2020$ Institute of Advanced Engineering and Science. All rights reserved.

\section{Corresponding Author:}

Vladimir Henao Céspedes,

Unidad Académica de Formación en Ciencias Naturales y Matemáticas,

Universidad Católica de Manizales,

Manizales-Colombia, Cra 23 No. 60-63, Colombia.

Email: vhenao@ucm.edu.co

\section{INTRODUCTION}

In recent years, levels of electromagnetic pollution (EMP) have increased, because the number of mobile devices has exceeded 5 billion, and it is estimated that the amount of them and the sensors associated with the internet of things (IoT) will reach 50 billion in the next decade [1, 2]. According to the IBSG (internet business solutions group), the birth of IoT occurs between 2008 and 2009, just when in the world for the first time were more devices connected to the Internet than people on the planet [3-5], and it is estimated that by 2020 there will be 6.58 Internet-connected devices per person.

The devices being connected are in turn generators and receivers of EM waves, which are emitted 24 hours a day. The scientific world, motivated by the possible risk factor of EMP for the environment and human health and considering the high number of EM wave generating devices, is interested in knowing more about the pollution that the devices can generate [6-9]. Regarding the impact of EMP on the environment, in [10-13] it is suggested that radiation from mobile phones is one of the many factors speculated to be responsible for the collapse of bee colonies and the decline in the sparrow population, so there are serious indications that EMP can affect any living ecosystem such as the human.

Considering then, the factor of possible environmental risk of the EMP, and the increase of base stations and devices that generate EM waves [14], in the present article a model is exposed to obtain the value of EMP, and to represent it in a graphical way on a map, allowing this way to evaluate the levels of pollution in a determined location. The document is organized as follows: Section 2 presents the review of the literature related to the measurement of electromagnetic pollution; section 3, presents the proposed 
electromagnetic pollution measurement methodology; section 4, gives an account of the measurement campaign carried out in the City of Manizales, applying the proposed measurement methodology, to elaborate the electromagnetic pollution map of the city, which is presented in the same section; section 5, concludes this work.

\section{EMP MEASUREMENT}

Regarding electromagnetic pollution measurement protocols, there is no explicit norm in the Colombian regulation, nor articles that detail an international measurement process. The authors who have contributed the most are those who are named below with their respective contributions, related to the measurement of electromagnetic field levels. Rappaport in [15], carries out a characterization study of UHF signals propagation inside buildings and homes. Rappaport, proposes that the measurement equipment, used for the characterization, be located in a site without immediate obstructions in the center of the measurement area. At a height of 2 meters with separations, from the measuring points, between 10 to 80 centimeters. On the other hand, Honcharenko in [16], performs measurements of electromagnetic fields, in order to study radio propagation in radio local area networks (R-LAN) and personal communication networks (PCN), in this study, proposes to perform the measurements by making a circular route with the measuring equipment over a spatial area, having linear dimensions of 10 to 20 wavelengths $(\lambda)$.

Trinchero in [17], performs a mapping of electromagnetic field levels associated with radio and television transmitters. To carry out the mapping, he establishes a mesh with points separated every 50 meters, this mesh is superimposed on the map of the city, thus defining the measurement points and locating the receiver equipment at a height of 1.80 meters On the other hand, Trinchero proposes that when the measurement of E exceeds the threshold of $1 \mathrm{~V} / \mathrm{m}$, or in streets with high field gradients, the separation is reduced to 10 meters.

Letertre in [18], performs electromagnetic field measurements at a frequency of $2.4 \mathrm{GHz}$, associated with broadband wireless access technologies (BWA). Letertre separates the measurements into two typologies: one is the global exposure measurement with a wideband isotropic probe and the other is the full exposure measurement using a selective frequency spectrum analyser, applying an extrapolation method. Letertre he proposes to apply a correction factor based on statistics from different measurement environments. Considering that each environment offers different characteristics for measurement, Thuróczy, in his study of exposure to radio frequencies in areas accessible to the public, states that the level of exposure is defined by the absorption and reflection of mountains, buildings, among others [19]. Thuróczy places the receiving equipment at an approximate height of $1.5 \mathrm{mt}$ and uses the peakhold mode that the equipment brings with it to measure on two or three axes. In relation to the different characteristics that can offer the environment to the measurements, the effect of the physical structure of the measurement sites was studied by Turin in [20]. Turin, proposes to carry out a characterization of the measurement sites, considering only indoor measurements, i.e. for outdoor measurements no characterization of the environment should be carried out.

\section{MEASUREMENT METHODOLOGY}

This document presents a case study in the city of Manizales, located in the department of Caldas, Colombia. The city, according to the projections of DANE (National administrative department of statistics) and the Statistical Information Center of the Municipal Planning Secretariat [21], has approximately 400.000 inhabitants. The city is located in the central part of the country, on the Central Mountain Range which is a branch of the Andes. Manizales has mountain topography, quite rugged, so it is necessary to install stations for mobile telecommunications in various parts of the city that can meet the communication requirements of the population in the urban area having a large number of telecommunications antennas in the city mainly mobile. For this reason, Manizales is a propitious scenario to make an EMP map, which allows evaluating how the EM radiation is spatially distributed. For the elaboration of the EMP map of the city, a measurement methodology was established that makes use of the immission measurement technique, considering that there are $\mathrm{n}$ radiation sources that contribute to the EMP value of the measurement site.

Considering that each of the $n$ sources is located in a coordinate $\left(x_{i}, y_{i}, z_{i}\right)$, it is possible to define the value of the total electromagnetic field measurement (TEMFM), at the measuring point $P\left(x_{d}, y_{d}, z_{d}\right)$ with the following expression:

$$
\operatorname{TEMFM}\left(\mathrm{x}_{\mathrm{d}}, \mathrm{y}_{\mathrm{d}}, \mathrm{z}_{\mathrm{d}}\right)=\sum_{\mathrm{i}=0}^{\mathrm{n}} \mathrm{F}_{\mathrm{i}}\left(\mathrm{x}_{\mathrm{i}}, \mathrm{y}_{\mathrm{i}}, \mathrm{z}_{\mathrm{i}}\right)
$$


The $n$ sources generate an electromagnetic pollution wave (EMPW), formed by the set of $n$, this set is represented by a vector of the $\mathrm{k}$-th sources, as follows:

$$
K=\left(f_{1}, f_{2} f_{3}, \ldots, f_{k}\right)
$$

To this vector $K$, a vector $A$ is associated, which contains the intensities $E$ or $H$, or the density of power $S$, according to the value measured with the instrument.

$$
A=\left(a_{1}, a_{2}, a_{3}, \ldots, a_{k}\right)
$$

Considering the above, $\operatorname{EMPW}(t)$ for a measurement point, will be the sum of all the intensities of the vector $A$ associated to $K$, obtaining:

$$
\operatorname{EMPW}(t)=\sum_{k=0}^{n} a_{k} e^{j k \omega_{k} t}
$$

where:

$n$ is the number of known present sources

$\omega_{\mathrm{k}}$ is the operating frequency of the k-th radiation source.

The above shows that EMPW is a complex wave, being composed by the contribution of the $n$ surrounding sources to the measurement point. Thus, all devices located in the electromagnetic environment are susceptible to receive the $E M P W$ signal, but process the components that their filters let pass. In the case of the human body, this one does not have filters that reject the diverse spectral components of $E M P W$, being susceptible to receive all the components of the signal.

Since EMPW is composed of the contribution of $n$ sources, as indicated by the expression (4), it is necessary to verify that sources are intermittent, i.e. they appear for short time intervals and in a random manner. If such sources exist, they should be included in the expression vector (2), since these, in light of the expression (4), also contribute to the EM pollution value.For each source vector element in (2) at each measurement site, a sampling time must be set. This time is defined as 6 minutes, as proposed by [22-25], and is established by the ICNIRP at [26]. If the source $k$ under analysis is intermittent, a sampling time of 20 minutes is proposed. Each measuring site shall be divided into $N$ measuring points, a mesh of dimensions $j * m$ shall be drawn over this area and a measurement shall be made in discrete mode, i.e. point-to-point. Once the measurements have been completed, for one of the vector elements (2), a spatial average of the values obtained from the measurements made in the mesh must be made, applying the expression (5):

$$
\text { average }=\frac{\sum_{j=0}^{\alpha} \sum_{m=0}^{\alpha} \operatorname{value}(j, m)}{N}
$$

Finally, after having the values of the measurements, the expression (4) is applied to calculate the total contribution of the radiation sources present in the measurement point or zone, as the case may be. In the flow chart in Figure 1, it is possible to visualize the measurement procedure for an area in a general way:

\section{RESULTS}

Using the measurement methodology, a measurement campaign was carried out in the city of Manizales, Colombia a shown in Figure 2. The measuring equipment used was the NARDA NBM-550 as shown in Figure 3 and Table 1, this is a broadband device, which is set to a frequency value. It has an isotropic measuring probe, allowing to measure $E, H$ or $S$ in the three spatial components $X, Y$ and $Z$. The measured value is the RSS (root sum square), expressed in the following equation:

$$
\sqrt{X^{2}+Y^{2}+Z^{2}}
$$

Table 1. Specifications of NBM-550

\begin{tabular}{cc}
\hline Measuring unit & $\mathrm{mW} / \mathrm{m}^{2}, \mathrm{~W} / \mathrm{m}^{2}, \mathrm{~V} / \mathrm{m}, \mathrm{A} / \mathrm{m}$ \\
\hline Types of results & Current, maximum, minimum, average, maximum average \\
Averaging time & 4 seg a 30 min $(2$ seg steps $)$ \\
Spatial average & Discreet or continuous \\
Storage capacity & Up to 5000 results \\
Memory & $12 \mathrm{MB}$ \\
GPS receiver type & Garmin, 12 satellite tracking channels, with DGPS correction \\
\hline
\end{tabular}

Int J Elec \& Comp Eng, Vol. 10, No. 4, August 2020 : 4244 - 4251 


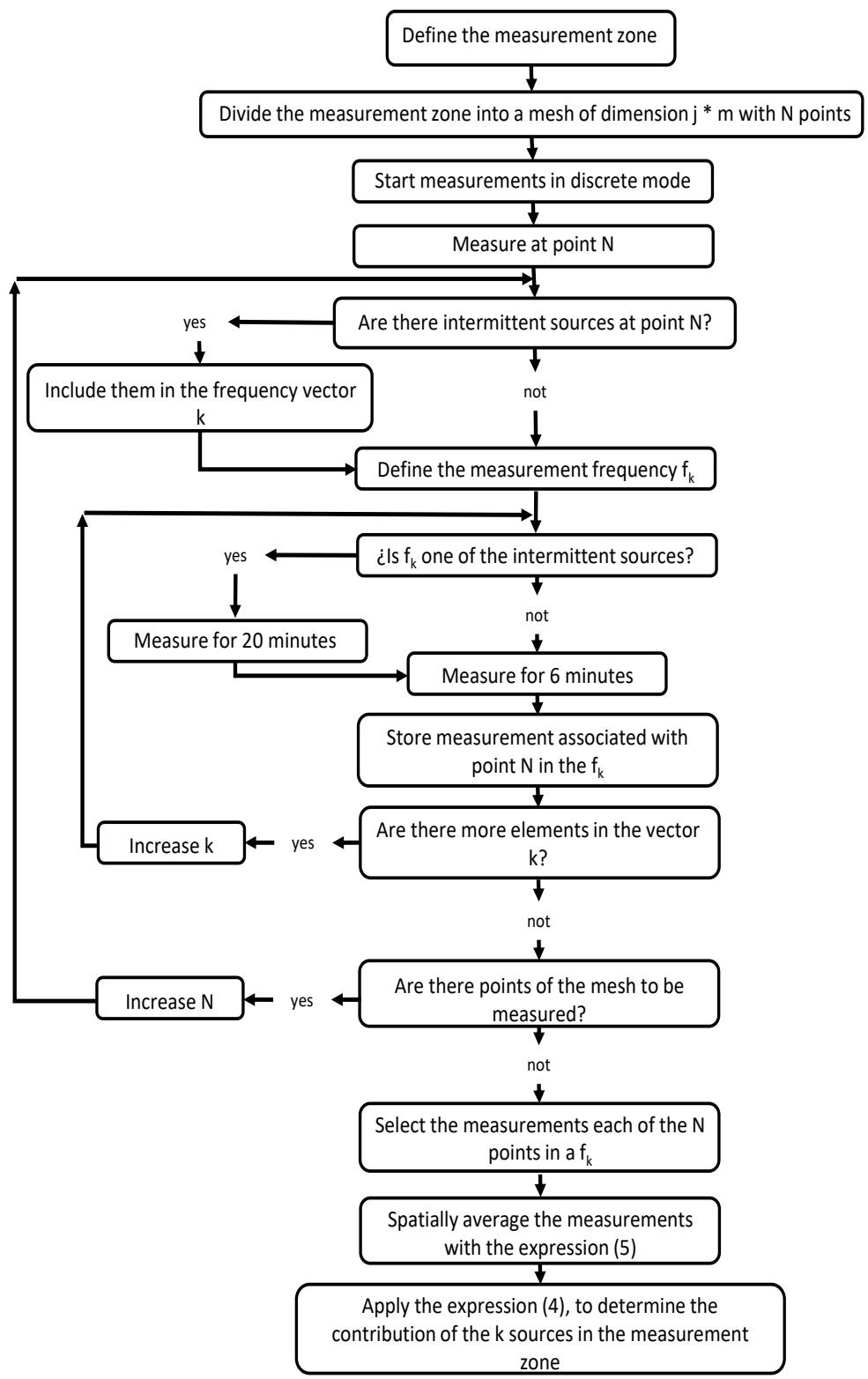

Figure 1. Flow chart of the measuring process
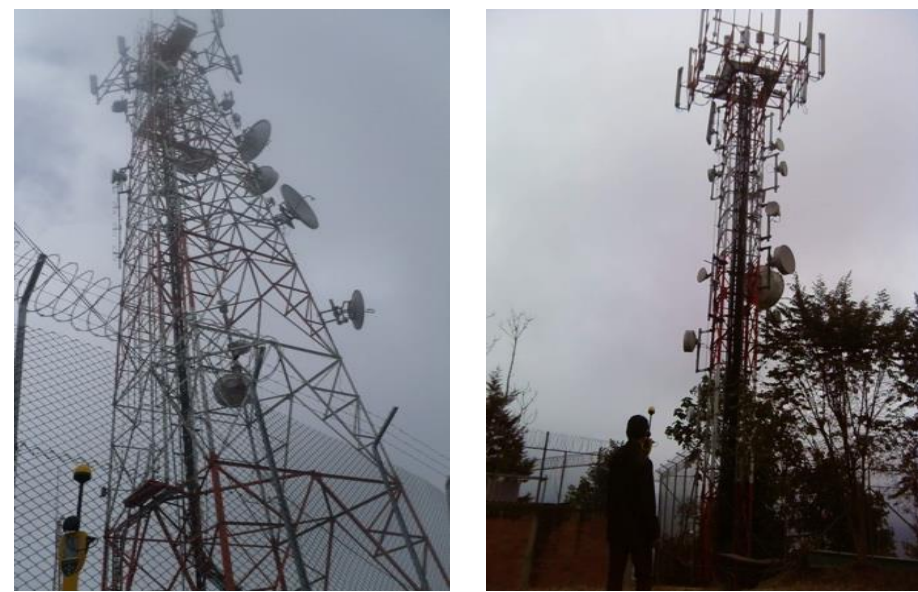

Figure 2. Measuring campaign 


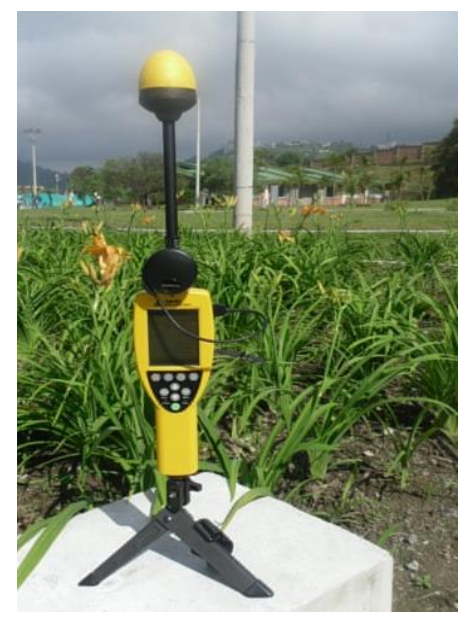

Figure 3. Measuring equipment NARDA NBM-550, with the probe $100 \mathrm{KHz}-3 \mathrm{GHZ}$ and on the front GPS GARMIN

For the City of Manizales the measurements were made in the urban area, that is to say, the sector of the center of the City and on the main roads. Starting from the hypothesis that in these sectors, higher levels of EMPW can be presented, due to the greater concentration of mobile phone base stations. The measurement frequencies of the source vector (2) for this measurement campaign are those of mobile phone operators in Colombia. $850 \mathrm{MHz}, 1900 \mathrm{MHz}$. In addition to these sources, the following bands were measured $900 \mathrm{MHz}$ (wireless telephony, and LPWAN Low Power Wide Area Network such as LoRaWAN and Sigfox) and $2.4 \mathrm{GHz}$ (Wi-Fi), related to IoT technologies, intermittent sources defined in the measurement methodology were also included. In relation to the frequencies selected to carry out the measurement campaign, the maximum permissible exposure limits, $E$ and $S$, in the general public zone, according to the laws of the Republic of Colombia [27], which is based on the ICNIRP regulations [26] as shown in Table 2.

Table 2. Maximum exposure limits

\begin{tabular}{cccc}
\hline Frequency $(\mathrm{MHz})$ & $\mathrm{S}\left(\mathrm{W} / \mathrm{m}^{\wedge} 2\right)$ & $\mathrm{E}(\mathrm{V} / \mathrm{m})$ & $\mathrm{H}(\mathrm{A} / \mathrm{m})$ \\
\hline 850 & 33.06 & 87 & 0.38 \\
1900 & 23.09 & 63 & 0.38 \\
2400 & 10 & 61 & 0.16 \\
\hline
\end{tabular}

\section{EMP MAP GENERATION}

After establishing the methodology for measuring electromagnetic pollution, a measurement campaign was carried out in the city of Manizales, the measurements obtained are captured in a risk map for electromagnetic pollution. In relation to electromagnetic pollution maps, Durduran in [22], presents a map for a city in Turqia, in its measurement procedure takes a single measurement, located $20 \mathrm{~m}$ away from the base station. On the other hand, Genc [25], using the technique of natural neighbor interpolation generates a map with ARCGIS, with the measurements in the GMS band, made from a vehicle in motion.

For the elaboration of the map, of the present article, a process of triangulation of Delaunay of the EM pollution measures was carried out, after these data have been geo-referenced with the geographical coordinates of the map. According to [28], Delaunay triangulation has as its main objective to establish a triangulation over a cloud of points in which the nearest points are connected by an edge or, in other words, in which the resulting triangles are as regular as possible. The recorded measurement values create a vector $[x, y, z]$ where $(x, y)$ are the coordinates of the measurement point, and $(z)$ represents the measured value. The coordinates $(x, y)$ refer to the terrain of the City of Manizales, and the terrain, is according to Berg [29], a two-dimensional surface in the 3-dimensional space with a special property as shown in Figure 4. Every vertical line that is crossed at a point, if it is crossed at all, i.e., the surface is the graph of a function $f: A \subset R 2 \rightarrow R$ that assigns a height $f(p)$ at each point $p$ in the domain, $A$, of the terrain, this assigned height is the value of EMPW. 


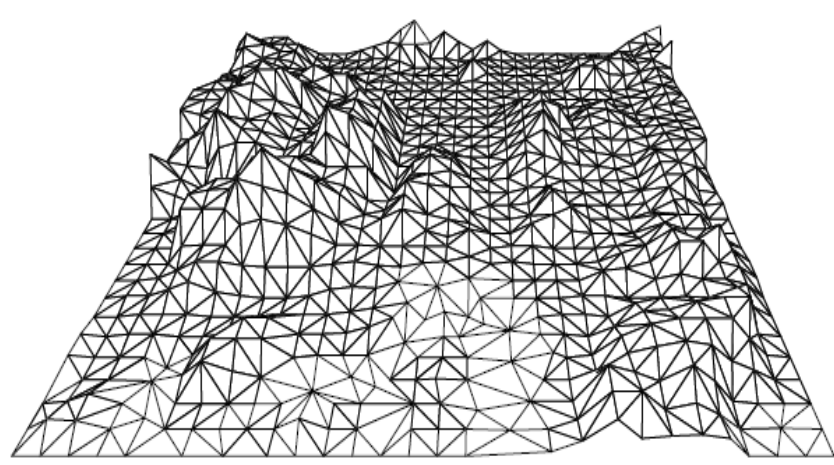

Figure 4. Perspective view of a plot of land [29]

The point cloud is the set of all the measurement data that cover the terrain of the City of Manizales, that is, if each point has an associated geo-referencing vector $P=[x, y, z]$ the total cloud of points will be:

$$
\left[\begin{array}{c}
{\left[x_{1}, y_{1}, z_{1}\right]} \\
{\left[x_{2}, y_{2}, z_{2}\right]} \\
\ldots \\
{\left[x_{n}, y_{n}, z_{n}\right]}
\end{array}\right]
$$

The map is elaborated locating in the coordinate $(x, y)$ the value of EMPW, after the campaign of measurements. The values of the measurements of electric field, magnetic field and power density, in different points of the city, and in the specified frequencies, are registered. Based on the recorded data, it is possible to obtain the z-value for the triangulation, which is then plotted, finally obtaining the COEM map as shown in Figures 5 and 6.

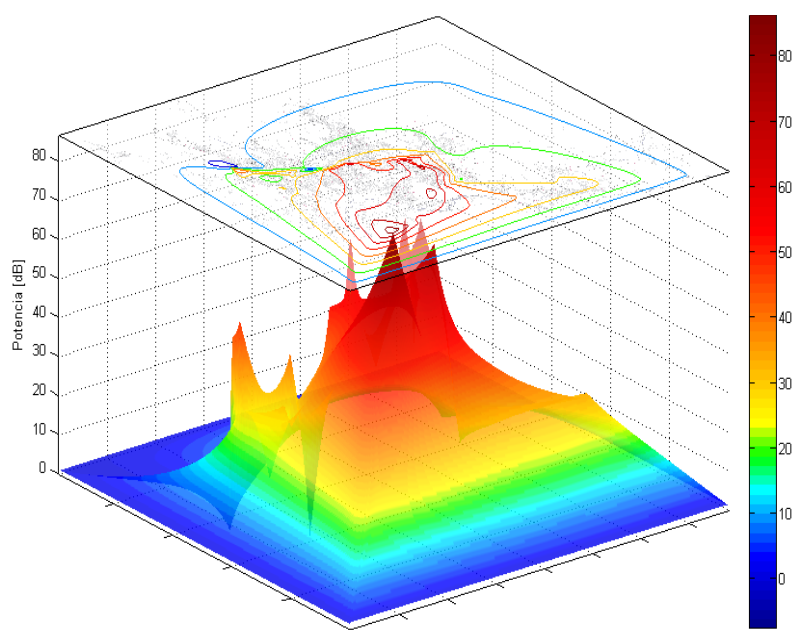

Figure 5. Perspective view of EMP levels in the City of Manizales

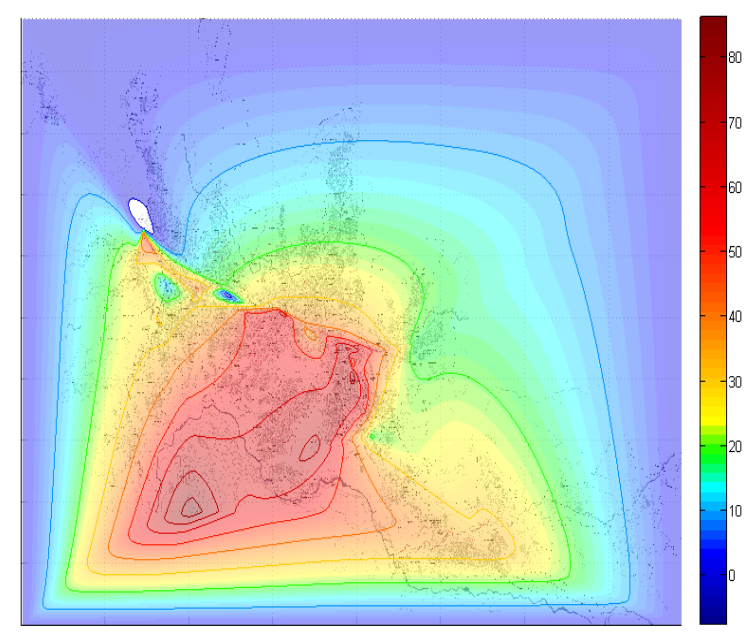

Figure 6. Top view EMP city of Manizales

The map shows that the levels of EM Pollution in the city are not homogeneous, due to the dispersion of existing EM radiation sources in Manizales. In the map, it is possible to see in red the points of the city where the EMP level is high and in blue the points of lower level. The levels in red color are towards the center of the city, sustaining as it had been previously said, that in where it is presented greater concentration of mobile communications base stations, it is the center of the city reflecting a greater level of EMP. The places with the lowest level of EMP, in green and blue, are located on the outskirts of the city, where the population is smaller and due to topographical and construction issues not too many base stations are required to cover the respective areas. 


\section{CONCLUSIONS}

In this article, a measurement methodology was proposed, which starts from considering that EMPW is not the contribution of a single source, and that on the contrary, it is the sum of the contributions of $\mathrm{n}$ sources. In this methodology, a measurement grid is proposed, with $\mathrm{N}$ points, at the measurement site, which can be a mobile phone base station. Also, a classification of intermittent sources is made in each measurement point, which will feed the vector of measurement sources. In relation to the risk map, case study and application, it is observed that the highest levels of EMPW in the city of Manizales are in the center of the city. This validates the starting hypothesis of the case study, which indicated that due to the high concentration of base stations, the EMPW levels are higher in the center of the city. Finally, it is expected that the map, will be included in the plans of territorial ordering of the City of Manizales, for the definition of the installation of new telephone base stations and other wireless communication technologies, generating a positive impact on environmental health.

\section{ACKNOWLEDGEMENTS}

This work was supported by the Universidad Nacional de Colombia, Sede Manizales with the Grupo de Investigación en Telemática y Telecomunicaciones GTT and Universidad Católica de Manizales with the research groups on Technological and Environmental Development GIDTA, and Education and Educators Traning EFE.

\section{REFERENCES}

[1] Ericsson Inc, "More than 50 Billion Connected Devices-Taking connected devices to mass market and profitability," 2011. [Online]. Available: https://vdna.be/publications/Wp-50-Billions.Pdf

[2] P. Baltre and R. Buckus, "Measurements and analysis of the electromagnetic fields of mobile communication antennas," Measurement, vol. 46, no. 10, pp. 3942-3949, 2013.

[3] D. Evans, "Cómo la próxima evolución de Internet lo cambia todo," Cisco IBSG, 2011.

[4] ITU, "Overview of the Internet of things (in Spanish)," (ITU-T Y.4000/Y.2060 (06/2012)), 2012.

[5] N. A. A. Bakar, W. M. W. Ramli, and N. H. Hassan, "The internet of things in healthcare: Anoverview, challenges and model plan for security risks management process," Indonesian Journal Electrtical Engineering Computer Science (IJEECS), vol. 15, no. 1, pp. 414-420, 2019.

[6] P. W. Release, "IARC classifies Radiofrequency Electromagnetic Fields as possibly carcinogenic to humans," Press Release, 2011.

[7] R. Affairs, S. Group, "The potential dangers of electromagnetic fields and their effect on the environment," Parliamentary Assembly Assemblee parlemtaire, 2011.

[8] P. D. Premlal and N. V. Eldose, "Mobile Tower Radiation and Its Impacts on Child Health: a Study Conducted in an Ecologically Sensitive Area of Western Ghats," International Journal Electrical Computer Engineering (IJECE), vol. 8, no. 6, pp. 4432-4437, 2018.

[9] S. R. A. Mutalik, et al., "A study of specific absorption rate in human head due to electromagnetic exposure to 4G signals," Indonesian Journal Electronic Engineering. Computer Science (IJEECS), vol. 13, no. 3, pp. 1161-1166, 2019.

[10] V. Shende and K. G. Patil, "Electromagnetic Radiations: A Possible Impact on Population of House Sparrow (Passer Domesticus),” Enginnering Int., vol. 3 pp. 45-52, 2015.

[11] J. Everaert and D. Bauwens, "A Possible Effect of Electromagnetic Radiation from Mobile Phone Base Stations on the Number of Breeding House Sparrows (Passer domesticus)," Electromagn. Biol. Med. vol. 26, no. 1, pp. 63-72, 2007.

[12] A. K. Dhami, "Study of electromagnetic radiation pollution in an Indian city," Environmental Monitoring and Assessment, vol. 184, no. 11, pp. 6507-6512, 2011.

[13] Y. S. Alwan, M. S. Zidan, and M.Q. Taha, "Evaluation of mobile microwave electric field severity at al-door residential complex in Iraq," Indonesian. Journal Electronic Engineering. Computer Science (IJEECS), vol. 14, no. 3, pp. 1281-1285, 2019.

[14] R. Roy and H. S. Saha, "Mitigation of the Excessive Non-ionized Radiation of Base Transceiver in Developing Countries," International Journal Information Network Security, vol. 1, no. 4, pp. 321-329, 2012.

[15] T. S. Rappaport and C. D. McGillem, "UHF Fading in Factories," in IEEE Journal on Selected Areas in Communications, vol. 7, no. 1, pp. 40-48, 1989.

[16] W. Honcharenko, et al., "Mechanisms Governing UHF Propagation on Single Floors in Modern Office Buildings," in IEEE Transactions on Vehicular Technology, vol. 41, no. 4, pp. 496-504, 1992.

[17] D. Trinchero, R. Tascone, et. al., "Exposure to high frequency electromagnetic fields in urban environments," in: Biannu. EMC Eur. Symp., 2002.

[18] T. Letertre, V. Monebhurrun, Z. Toffano, "Electromagnetic Field Measurements of WIMAX Systems using Isotropic Broadband Probes," in IEEE MTT-S IEEE MTT-S International Microwave Symposium, pp. 1-4, 2011.

[19] G. Thuroczy et al., "Public exposure to RF from installed sources: Site measurements and Personal Exposimetry," First European Conference on Antennas and Propagation, pp. 1-4, 2006 
[20] G. L. Turin, F. D. Clapp, T. L. Johnston, S. B. Fine and D. Lavry, "A statistical model of urban multipath propagation," in IEEE Transactions on Vehicular Technology, vol. 21, no. 1, pp. 1-9, 1972.

[21] Manizales "Alcaldía de Manizales-Secretaría de Educación, Boletín Estadístico," 2017, [online]. Available: https://manizales.gov.co/RecursosAlcaldia/201904092249175840.pdf.

[22] S. S. Durduran, O. Uygunol, L. Seyfi, "Mapping of electromagnetic pollution at $1800 \mathrm{MHz}$ GSM (global system for mobile communication) frequency in Konya," Scientific research and essays, vol. 5, vol. 18, pp. 2664-2672, 2010.

[23] Ç. Kurnaz, "An Empirical Modeling of Electromagnetic Pollution on a University Campus," Applied Computational Electromagnetics Society Newsletter, vol. 33, no. 1, pp. 76-79, 2018.

[24] Ş. Ç. Yener, O. Çerezci, Ş.S. Şeker, "Determination of the electromagnetic pollution in local school indoor and outdoor environments," Istanbul University-Journal of Electrical and Electronics Engineering, vol. 17, no. 2, pp. 3509-3515, 2017.

[25] Ö. Genc, M. Bayrak, E. Yaldiz, "Analysis of the effects of GSM bands to the electromagnetic pollution in the RF spectrum," Progress In Electromagnetics Research, vol. 101, pp. 17-32, 2010.

[26] I.C. on N.-I.R., "Protection, Icnirp Guidelines For Limiting Exposure To Time-Varying Electric," Magnetic and Electromagnetic, 1999.

[27] M. tecnologías de la información y las comunicaciones, Decreto 1370 de 02 de Agosto del 2018, Mininformación, Colombia, 2018. [Online]. Available: https://dapre.presidencia.gov.co/normativa/normativa/DECRETO 1370 DEL 02 DE AGOSTO DE 2018.pdf.

[28] L. Tortosa Grau, V.F. Francisco, "Geometría Moderna para Ingeniería," Editorial ECU, 2012.

[29] M. de Berg, O. Cheong, M. van Kreveld, M. Overmars, "Computational Geometry Algorithms and Applications," Third Edit, Springer, Berlin, 2008.

\section{BIOGRAPHIES OF AUTHORS}

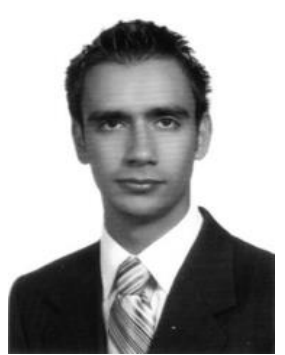

Vladimir Henao Céspedes: received the B.S degree in electronic engineering, the M.Sc. degree and the PhD. On engineering from Universidad Nacional de Colombia, Manizales. He currently an Associate Professor in the Unidad Académica de Formación en Ciencias Naturales y Matemáticas, at the Universidad Católica de Manizales, Manizales. His research interests include electromagnetic compatibility, electromagnetic pollution, and lightning discharges. He is member of the Research Group on Tecnhonological and Environmental Development GIDTA. E-mail: vhenao@ucm.edu.co; http://orcid.org/0000-0002-1938-3203.

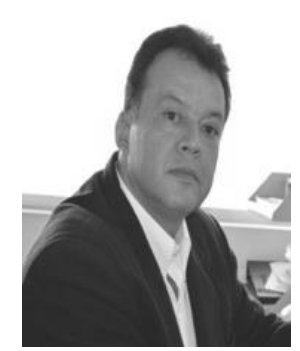

L. F. Díaz-Cadavid: He received the degrees in Telecommunications Engineering and M. Sc in automatic telecommunication from the The Bonch-Bruevich Saint-Petersburg State University of Telecommunications, Saint Petersburg, Russia, in 1982 and 1984 respectively. He received specialist degree in informatics and computing from the University of Cantabria, Spain, in 1995, and the Ph. D degree in automatic engineering from the Universidad Nacional de Colombia, Manizales, Colombia, in 2014. He is Associate Professor at the Universidad Nacional de Colombia, Manizales, and is currently the Director of the Grupo de investigación en Telemática y Telecomunicaciones GTT, Manizales. https://orcid.org/0000-0001-6073-5437

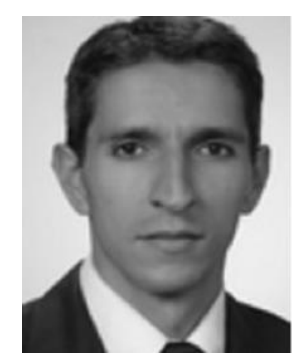

Yeison A. Garces: Electrical Engineer, M.Sc (Eng) Industrial Automation, Ph.D. on Engineering. Associated Professor, UAFCNM, Universidad Católica de Manizales, Manizales, Colombia. His research interests include power definitions under no sinusoidal conditions, power quality analysis, and power electronic applications. He is member of the Research Group on Tecnhonological and Environmental Development GIDTA and Education and Educators Traning EFE. E-mail: ygarces@ ucm.edu.co; http://orcid.org/0000-0002-9409-3652 